\title{
Correlation of sintered microstructure with green density in thick-film PZT
}

\author{
L.Mortara $^{1}$, A. Navarro ${ }^{1}$, R.W. Whatmore ${ }^{1}$ and J.R. Alcock ${ }^{1}$ \\ ${ }^{1}$ Advanced Materials, School of Industrial and Manufacturing Science, Cranfield University, \\ Bedfordshire, MK43 OAL, UK \\ e-mail:L.Mortara.2001@cranfield.ac.uk; J.R.Alcock@cranfield.ac.uk
}

Keywords: Tape casting, Green Density, Microstructure, Sintered Density.

\begin{abstract}
High density and low grain size are essential for the production of thick-film ceramics, in order that they possess adequate strength for any subsequent processing steps. In this paper sintered density and grain size were studied as function of green density and firing temperature. Wafers possessing a higher green density showed a more homogeneous microstructure and a higher sintered density.
\end{abstract}

\section{Introduction}

The tape casting technique is widely used industrially to produce thin and flat ceramic wafers for a broad range of applications [1]. The ceramics, in the majority of the cases, undergo several post sintering steps, which involve a mechanical stress. Thus, a high process yield, in such operations as poling, machining and dicing, is directly related to a more than adequate strength.

As is well known, strength in ceramics is dependent on peak flaw size and therefore on the grain size and porosity of the microstructure [2]. A small grain size and, generally, a high final density, contribute to high strength. The attainment of such a final microstructure in the ceramic is the result of many factors, which could be grouped in two main categories: the green ceramic characteristics and the sintering conditions [3].

This paper investigates the variation of sintered density and grain size with green density and sintering temperature, for thick-film PZT.

\section{Experimental}

Navarro et al. [4,5] developed an aqueous laboratory tape casting process for use with PZT powders. The experimental conditions developed for this process are described elsewhere [4,5]. The PZT powder used in these experiments has a density of $8.17 \mathrm{~g} / \mathrm{cm}^{3}$, according to XRD analysis, and average particle size of $(1 \pm 0.3) \mu \mathrm{m}$ from particle size analysis (ESA). In this paper, densities are quoted as percentage of the theoretical value of $8.17 \mathrm{~g} / \mathrm{cm}^{3}$. The green density produced by this process varies, amongst other reasons, with the degree of cross linking of the binder. Aged, highly cross linked polymer can yield a green density as low as $3.03 \mathrm{~g} / \mathrm{cm}^{3}(37 \%)$, from slurries of solid weight content of $67 \%$. This was used as the lowest green density for this study.

Fig 1:

A)

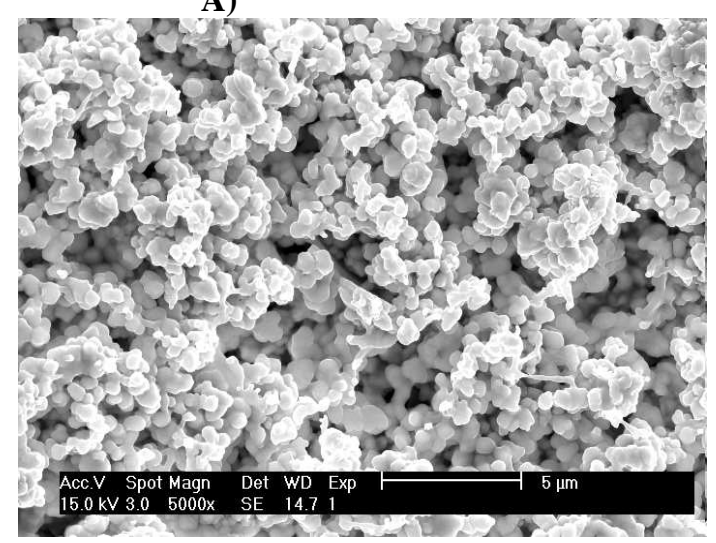

B)

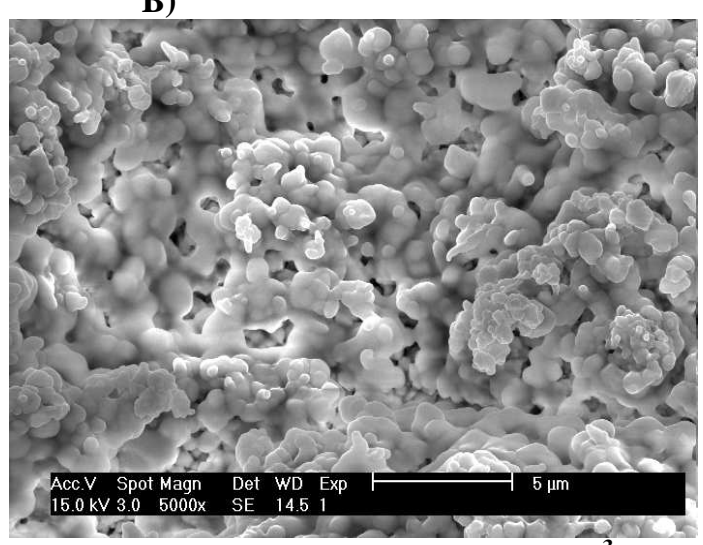

hick film of green density of $3.03 \mathrm{~g} / \mathrm{cm}^{3}$

B) Fracture surface of warm pressed tape cast thick film of green density of $5.29 \mathrm{~g} / \mathrm{cm}^{3}$

Green tapes were warm pressed at pressures between 50 and $250 \mathrm{MPa}$, over a temperature range between 40 and $50{ }^{\circ} \mathrm{C}$ and a dwell time of 15 or $20 \mathrm{~min}$. The Tg of the binder system was $39^{\circ} \mathrm{C}$. This 
procedure allowed samples with green density between 3.7 and $5.3 \mathrm{~g} / \mathrm{cm}^{3}(45-65 \%)$ to be produced. The green density of the samples was calculated after the pressing stage by measurement of the sample dimensions and weight. Fig 1A shows a sample with a green density of $3.03 \mathrm{~g} / \mathrm{cm}^{3}$. Fig $1 \mathrm{~B}$ illustrates the structure of a pressed green sample, with density of $5.29 \mathrm{~g} / \mathrm{cm}^{3}$, where the porosity has been noticeably reduced in size and amount. The quantity of polymer in the two cases is the same, but its volume fraction is higher in Fig.1B as the air amount has been reduced.

Samples with green density of $37.1 \%$ (A), $58.6 \%$ (B) and $64.7 \%$ (C) were chosen to be sintered at temperatures of either 1210 (1) or 1170 (2) ${ }^{\circ} \mathrm{C}$ for $45 \mathrm{~min}$ in a lead rich atmosphere. The heating rate was $3^{\circ} \mathrm{C} / \mathrm{min}$. Subsequently, the sintered density of the samples was calculated using the Archimedes methodology [6].

The microstructure of the green tapes and sintered ceramics was examined by SEM. The average grain size and the standard deviation were calculated from measurements of 20 grains for each microstructure.

\section{Results and Discussion}

Table 1: Densities and grain sizes of green material and sintered tapes

\begin{tabular}{|c|c|c|c|c|c|c|c|c|}
\hline & $\begin{array}{c}\text { Sintering } \\
\text { temp. } \\
{\left[{ }^{\circ} \mathbf{C}\right]}\end{array}$ & $\begin{array}{l}\text { Green } \\
\text { density } \\
{\left[\mathrm{g} / \mathrm{cm}^{3}\right]}\end{array}$ & $\begin{array}{c}\text { Green } \\
\text { density }^{1} \\
{[\%]}\end{array}$ & $\begin{array}{c}\begin{array}{c}\text { Sintered } \\
\text { density } \\
{\left[\mathrm{g} / \mathrm{cm}^{3}\right]}\end{array} \\
\end{array}$ & $\begin{array}{c}\text { Sintered } \\
\text { density }^{1} \\
{[\%]}\end{array}$ & $\begin{array}{c}\text { Grain size } \\
\text { average } \\
{[\mu \mathrm{m}]}\end{array}$ & $\begin{array}{l}\text { Standard } \\
\text { deviation }\end{array}$ & $\begin{array}{c}\text { Grain size } \\
\text { range } \\
{[\mu \mathrm{m}]} \\
\end{array}$ \\
\hline A1 & 1210 & 3.03 & 37.1 & 6.91 & 84.6 & 5.5 & 1.75 & $3.1-9.1$ \\
\hline B1 & 1210 & 4.79 & 58.6 & 7.65 & 93.6 & 9.1 & 2.67 & $2.8-12.2$ \\
\hline C1 & 1210 & 5.29 & 64.7 & 7.82 & 95.7 & 8.3 & 2.58 & $4.1-13.1$ \\
\hline$\overline{A 2}$ & 1170 & 3.03 & 37.1 & 6.84 & 83.7 & 3.9 & 2.12 & $1.6-8.4$ \\
\hline B2 & 1170 & 4.79 & 58.6 & 7.62 & 93.3 & 7.3 & 2.64 & $3.1-12.2$ \\
\hline C2 & 1170 & 5.29 & 64.7 & 7.95 & 97.3 & 7.0 & 2.16 & $3.4-10.3$ \\
\hline
\end{tabular}

Fig 2:

A)

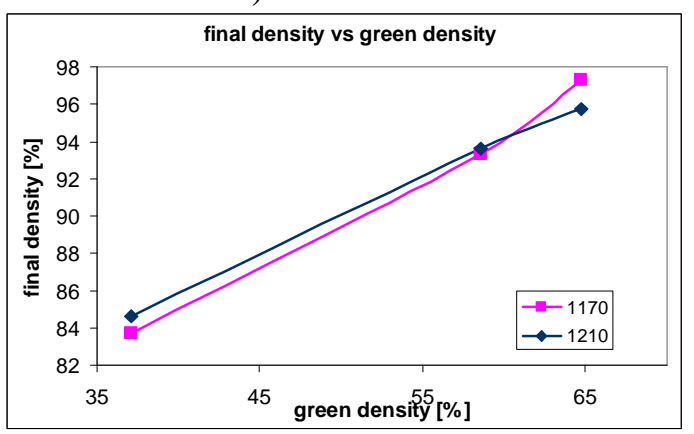

B)

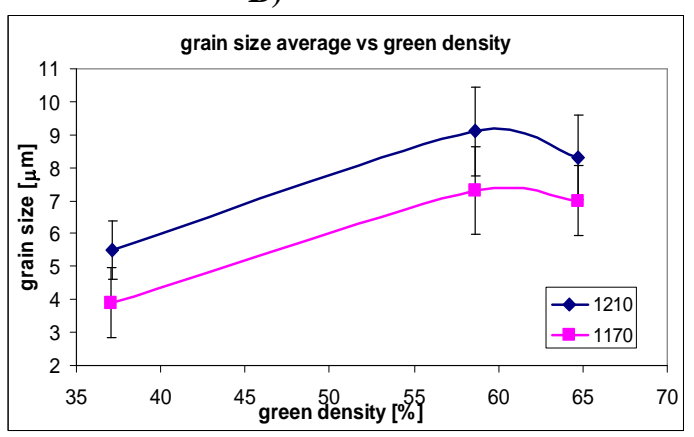

A) Graph of the variation of the sintered density against the variation of the green density B) Graph of the variation of the grain size average against the variation of the green density

Table 1, Fig. 2 and Fig. 3 illustrate the development of the sintered density and the average grain size as a function of increasing green density.

There is a strong correlation between high green density and high sintered density. However, a $40{ }^{\circ} \mathrm{C}$ variation in sintering temperature had little effect on density. At $1210{ }^{\circ} \mathrm{C}$ a $27.6 \%$ increase, from $37 \%$ (A) to $65 \%(\mathrm{C})$, of the green density gave an improvement in the sintered density of $11 \%$, while at 1170 ${ }^{\circ} \mathrm{C}$ it gave an increase of $13.6 \%$. In contrast, the increasing of sintering temperature from $1170^{\circ} \mathrm{C}$ to $1210^{\circ} \mathrm{C}$, for a constant green density, produced a negligible increase in the final sintered density, of about $1 \%$, for the $37 \%$ (A) green density. For $65 \%$ (C) green density the sintered density actually diminished by $1.6 \%$. On the other hand, the average grain size appeared to be influenced by both the variation in the firing temperature and by the increase in green density.

\footnotetext{
${ }^{1}$ Percentage of theoretical
} 
Fig 3: Fracture surfaces of sintered microstructures



A general trend of the development of the ceramic microstructure whilst varying the green density (A), (B) and (C) could be observed for both sintering profiles (1) and (2), as described below:

- The sintering of 37\% (A) green density (Fig. 3: A1 and A2), resulted in an incomplete intermediate stage sintering with fired density of approximately 84\%; the open porosity was still abundant and positioned in the triple point; the grains had average dimensions of 5.5 and $3.9 \mu \mathrm{m}$ respectively, with non uniform shapes. Dense areas, which could be correlated with agglomerates in the green state (Fig.1A), alternated with more porous ones.

- Green bodies of 59\% (B) green density (Fig. 3: B1 and B2), showed a generally higher degree of sintering, producing a sintered density of about $93 \%$. The microstructure showed higher average grain size (averages 7.3 and $9.1 \mu \mathrm{m}$ respectively), and lower porosity. The microstructure was compatible with an over-sintered state: the porosity was closed and positioned both at the triple point and in the cores of the grains; the grains exhibited strong coarsening.

- The samples obtained from the 65\% (C) green density material (Fig. 3: C1 and C2) showed high sintered density (95-97\%) and an improved microstructure: grain size averages of 7.0 and $8.3 \mu \mathrm{m}$, with little residual porosity, located mainly at the triple point.

In general, varying the sintering profile from $1210^{\circ} \mathrm{C}$ to $1170^{\circ} \mathrm{C}$ produced the following effects:

- The grain size was reduced.

- The average grain size showed a smaller decrease for the higher green density thick film.

It is evident for the tapes at the lowest (37\%) (Fig. 3: A1 and A2) and intermediate (59\%) (Fig. 3: B1 and B2) green density that, by starting from a low density ceramic the grain coarsening effect was dominant in comparison to the increasing of the ceramic density. While for the low density (A) the sintering temperature was insufficient for complete densification, the intermediate density (B) achieved a state of apparent over-sintering. However, the samples with green density of about $65 \%$ (C) microstructure (Fig. 3: $\mathrm{C} 1$ and $\mathrm{C} 2$ ), showed a different correlation between densification and grain growth, exhibiting smaller grains and higher density. 
This seem to indicate that while for the green densities (A) and (B) the distance among some particles and/or agglomerates is large and, hence, the particle/agglomerates number coordinated by a pore is high (Fig.1A), for high green densities (C) most of the pores have dimensions comparable with the grain size (Fig.1B) and consequently, a lower particle coordination number. As a result, the sintering mechanism appears to be differentiated between low green densities like (A) or (B) (porous) and (C) (less porous).

A mechanism for the sintering of highly porous bodies has been suggested by Greskovich and Lay [7]: when particles of slightly different size are in contact, the neck grows mainly by surface diffusion, migrating from the contact plane, and consuming the smaller grain [8]. This mechanism extended to a cluster of particles generates a large granule. At this stage, both neck growth and the boundary relocation in the less porous areas would drive the coarsening of the grains. As sintering progresses, the ceramic microstructure will evolve areas of different density similar to those shown in Fig 3. A1 and A2. If the grain-boundary migration is rapid, it can, for a certain green density, trap the pores in the cores of the grains as shown in Fig. $3 \mathrm{~B} 1$ and B2. This will therefore alternate conventional grain growth to porous body grain growth. As new contacts between growing grains occur, less faceted grains are created (Fig. $3 \mathrm{~B} 1$ and B2).

More dense green ceramics (C) instead seem to have a slower grain-boundary motion, as the intermediate stage of the sintering would see a more uniform microstructure. This allows the pores to move to the boundary. Ordinary grain growth and densification rates happen in these circumstances.

\section{Conclusions}

The study presented in the paper highlights how increasing the green density has a great impact on the sintering mechanism. The sintered density was greatly enhanced by the increase of the green density reaching $7.95 \mathrm{~g} / \mathrm{cm}^{3}, 97.3 \%$ of the theoretical value, for a $65 \%$ green density. In contrast, a $40^{\circ} \mathrm{C}$ increase in sintering temperature had a negligible effect in density. High green density wafers showed noticeably reduced porosity, along with a narrower grain size distribution.

The results achieved suggested that the sintering mechanism varied depending on the initial green density. For the material used in this study, the grain coarsening was dominant for densification of more porous bodies of green density approximately $37 \%$ and became less important as long as the starting density reached values of about $65 \%$.

\section{References}

[1] R. E Mistler: J.Am. Soc. Bulletin Vol. 69 (1990), p. 1022-26

[2] D.W. Richerson: Modern Ceramic Engineering (Marcel Dekker, New York 1992), p 171

[3] M. N. Rahman: Ceramic processing and Sintering, (Marcel Dekker, New York 1995), p 333

[4] A. Navarro, J.R. Alcock, R.W. Whatmore: J. Eur.Ceram. Soc. (2002). In publication.

[5] A. Navarro, J.R. Alcock, R.W. Whatmore: Ferroelectric UK (2001), p. $93-99$

[6] Y-B. P. Kwan, J.R. Alcock: J. Mat. Sci. Vol. 37 (2002), p. 2557-61

[7] C. Greskovich, K.W.Lay: J. Am. Ceram. Soc. Vol. 55 (1972), p. 142-48

[8] L. H. Edelson, A.M. Gleaser: J. Am. Ceram. Soc. Vol. 71 (1988), p. 225-35

\section{Acknowledgements}

This work would not have been possible without the support of the UK DTI TCS scheme. The author acknowledges Mr Paul Osbond for his constant and highly valuable support and Mr Colin Matthews for his kind help. 